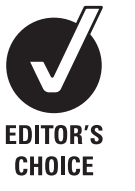

'Department of Neurology, Ospedale Ca'Foncello, Treviso, Italy

${ }^{2}$ Nuffield Department of Clinical Neurosciences, University of Oxford, Oxford, UK

${ }^{3}$ Service of Neurology, Hospital Clinic, and Institut d'Investigacio' Biomedica August Pi i Sunyer (IDIBAPS), Barcelona, Spain

${ }^{4}$ Epilepsy Centre Bethel, Krankenhaus Mara, Bielefeld, Germany

Correspondence to Professor A Vincent, Nuffield Department of Clinical Neurosciences, University of Oxford, John Radcliffe Hospital, Oxford OX3 9DU, UK; angela. vincent@clneuro.ox.ac.uk

Received 21 August 2011 Revised 29 January 2012 Accepted 31 January 2012 Published Online First 24 March 2012

\title{
Central nervous system neuronal surface antibody associated syndromes: review and guidelines for recognition
}

\author{
Luigi Zuliani, ${ }^{1}{ }^{1}$ Francesc Graus, ${ }^{3}$ Bruno Giometto, ${ }^{1}$ Christian Bien, ${ }^{4}$ Angela Vincent ${ }^{2}$
}

\begin{abstract}
The concept of antibody mediated CNS disorders is relatively recent. The classical CNS paraneoplastic neurological syndromes are thought to be T cell mediated, and the onconeural antibodies merely biomarkers for the presence of the tumour. Thus it was thought that antibodies rarely, if ever, cause CNS disease. Over the past 10 years, identification of autoimmune forms of encephalitis with antibodies against neuronal surface antigens, particularly the voltage gated potassium channel complex proteins or the glutamate N-methyl-D-aspartate receptor, have shown that CNS disorders, often without associated tumours, can be antibody mediated and benefit from immunomodulatory therapies. The clinical spectrum of these diseases is not yet fully explored, there may be others yet to be discovered and some types of more common disorders (eg, epilepsy or psychosis) may prove to have an autoimmune basis. Here, the known conditions associated with neuronal surface antibodies are briefly reviewed, some general aspects of these syndromes are considered and guidelines that could help in the recognition of further disorders are suggested.
\end{abstract}

\section{INTRODUCTION}

Well recognised conditions such as myasthenia gravis (MG) and the Lambert-Eaton myasthenic syndrome (LEMS) have been shown by rigorous experimental approaches to be antibody mediated. The antibodies are directed against essential membrane receptors or ion channels involved in transmission at the neuromuscular junction; the antibodies bind to extracellular epitopes on the membrane proteins; plasma exchange leads to clear clinical benefit; and both in vitro and passive transfer experiments show that the IgG antibodies are pathogenic. ${ }^{1}$

Several antibodies to 'onconeural' antigens are found in CNS disorders associated with cancers (paraneoplastic neurological syndromes), ${ }^{2-4}$ including antibodies to $\mathrm{Hu}$ (Hu-Abs), and many others. ${ }^{5}$ However, as the targets of these antibodies are intracellular proteins, and patients do not usually improve with immunotherapy, their pathogenic roles are not clear. Rather, it is thought that $\mathrm{T}$ cell cytotoxicity is a more likely mechanism to account for the neuronal cell loss that occurs in these rare but serious conditions. T cell cytotoxicity could also contribute in patients with antibodies to glutamic acid decarboxylase (GADAbs) as these are also directed against an intracel- lular antigen, but at very high levels are associated with non-paraneoplastic forms of stiff person syndrome (SPS) and other CNS disorders. ${ }^{67}$

Over the past few years it has become increasingly clear that there are CNS syndromes associated with antibodies that bind to cell surface determinants of membrane associated proteins on neuronal cells and are likely to be pathogenic. ${ }^{89}$ Here we call these antibodies 'neuronal surface antibodies' (NSAbs), and the diseases associated with them, NSAb syndromes (NSAS). These syndromes can be indistinguishable at presentation from classical paraneoplastic syndromes, such as limbic encephalitis (LE), but one is a newly defined entity, $\mathrm{N}$-methyl-D-aspartate receptor antibody (NMDAR$\mathrm{Ab}$ ) encephalitis. ${ }^{10}$ These syndromes can be diagnosed by serum/CSF antibody tests, are not so rare, are frequently non-paraneoplastic and they respond to immunotherapy with a good chance of substantial recovery. ${ }^{8-12}$

Although these syndromes are beginning to be widely recognised, there are likely to be others for which no NSAb has yet been defined and in which immunotherapies have not yet been tested. There is a need, therefore, to define guidelines for their recognition so that an immune mediated basis can be explored. In this review, we start by comparing conditions that are associated with antibodies to intracellular antigens with those that are associated with antibodies to cell surface antigens. We then summarise the main clinical and paraclinical features of the syndromes that have already been identified and, largely from these observations, suggest guidelines for recognising these and other immune mediated conditions in the future. We concentrate on the diseases predominantly affecting the 'grey' matter, and will not include those diseases such as neuromyelitis optica and acute disseminated encephalomyelitis in which antibodies to 'white' matter glial or myelin antigens have also recently been discovered. ${ }^{13} 14$

\section{GENERAL FEATURES OF DISEASES ASSOCIATED WITH ANTIBODIES TO INTRACELLULAR ANTIGENS VERSUS THOSE WITH NSABS}

Table 1 summarises some features of the CNS autoimmune syndromes according to the presence of onconeural antibodies or NSAbs. Patients with onconeural Abs present at ages which are typical of the tumours but those with NSAbs can occur at any age. LE and the more complex NMDAR-Ab encephalopathy are, to date, the most frequent 
Table 1 CNS syndromes associated with antineuronal antibodies

\begin{tabular}{|c|c|c|}
\hline & $\begin{array}{l}\text { Classical paraneoplastic CNS syndromes } \\
\text { associated with onconeural antibodies }\end{array}$ & $\begin{array}{l}\text { CNS syndromes associated with neuronal } \\
\text { surface antibodies }\end{array}$ \\
\hline Main syndromes & $\begin{array}{l}\text { PCD } \\
\text { Encephalomyelitis } \\
\text { LE } \\
\text { Brainstem encephalitis }\end{array}$ & $\begin{array}{l}\text { LE } \\
\text { Morvan's syndrome } \\
\text { NMDAR-Ab encephalitis } \\
\text { PERM } \\
\text { Cerebellar ataxia }\end{array}$ \\
\hline Age range (years) and sex & $\begin{array}{l}\text { Mainly adults }(40-70) \text {; both genders } \\
\text { (PCD more frequent in women). }\end{array}$ & $\begin{array}{l}\text { NMDAR-Ab encephalitis common in children } \\
\text { and young women }\end{array}$ \\
\hline $\begin{array}{l}\text { Antibodies commonly detected or } \\
\text { recently reported }\end{array}$ & $\begin{array}{l}\text { Antibodies against intracellular antigens } \\
\text { or PNS related onconeural antibodies } \\
\text { (Hu, Yo, Ri, Ma2, Cv2/CRMP5, amphiphysin, Sox1/2) }\end{array}$ & $\begin{array}{l}\text { Antibodies to VGKC complex antigens } \\
\text { (LGI1 or CASPR2), NMDAR, AMPAR, } \\
\text { GABA }_{B} R \text {, GlyR, VGCC-Ab, mGluR1, mGluR5* }\end{array}$ \\
\hline Tumours & SCLC, breast, ovary, testicular & $\begin{array}{l}\text { Teratoma, thymoma, SCLC, breast } \\
\text { No tumour found in many cases, particularly } \\
\text { LE associated with LGI1-Ab }\end{array}$ \\
\hline $\begin{array}{l}\text { Relationship between antibody } \\
\text { and tumour }\end{array}$ & $\begin{array}{l}\text { Antibody usually indicates the presence } \\
\text { of a particular tumour type }\end{array}$ & $\begin{array}{l}\text { Antibody presence does not indicate } \\
\text { if a case is paraneoplastic }\end{array}$ \\
\hline Immunotherapy & Not usually effective & Generally effective \\
\hline Outcome & $\begin{array}{l}\text { Poor; improvement or stabilisation related } \\
\text { mainly to tumour treatment }\end{array}$ & $\begin{array}{l}\text { Variable but generally good; possible } \\
\text { spontaneous remission }\end{array}$ \\
\hline Neuropathology & $\begin{array}{l}\text { Loss of neurons, gliosis, T cell infiltrates in } \\
\text { close apposition to neurons, some with } \\
\text { immunophenotype of cytotoxic T cells }\end{array}$ & $\begin{array}{l}\text { Limited data Variable T cells, } \\
\mathrm{B} \text { cells and plasma cell infiltrates but less } \\
\text { intense than in patients with paraneoplastic } \\
\text { disease. }^{9 \mathrm{a}}\end{array}$ \\
\hline Prevalent pathogenic mechanism & $\begin{array}{l}\text { Antibodies are markers for the tumour and } \\
\text { are not likely to be pathogenic. T cell } \\
\text { cytotoxicity is the proposed pathogenic } \\
\text { mechanism }\end{array}$ & $\begin{array}{l}\text { Autoantibody mediated, probably downregulation } \\
\text { of target antigen but may be complement } \\
\text { mediated damage in some conditions }\end{array}$ \\
\hline
\end{tabular}

presentations in the NSAS and more common than either cerebellar degeneration or encephalomyelitis with onconeural/ intracellular antibodies. Tumours can be present, particularly small cell lung cancer (SCLC), ovarian and breast cancers with onconeural antibodies, and ovarian teratomas, thymomas, breast and lung cancers with the NSAS, but many of the NSAS patients do not have tumours. Evidence of CSF inflammation, including oligoclonal bands, can be present in both groups but a normal CSF is more common with some of the NSAS. ${ }^{2} 389$

The most important distinctions relate to the course and treatment responses. Patients with onconeural antibodies usually present subacutely and often have a relentlessly progressive course, despite immunotherapies, although there may be stabilisation of the neurological syndrome if tumour treatment is effective. ${ }^{4}$ By contrast, patients with NSAbs may have an acute or subacute onset, usually with short duration to nadir, and can make a very good response to immunotherapies. In additions to tumour treatment if required; in many cases immunotherapies can be weaned over a year or two, suggesting that the condition is monophasic. ${ }^{8}$

It is generally accepted that the onconeural antibodies are markers for the immune mediated process but not pathogenic; T cell cytotoxicity towards the same or other antigens is thought to be causative, mostly based on postmortem observations of abundant $\mathrm{T}$ cell infiltrates in the brain parenchyma in close apposition with neurons. The NSAS are not well studied yet but $T$ cell infiltration is less conspicuous in the few reports of patients with anti-NMDAR encephalitis. ${ }^{4} 68$

WELL DEFINED CNS SYNDROMES ASSOCIATED WITH NSABS

Features of the main syndromes recognised so far are summarised in table 2. NSAbs have, of course, been described in the neuromuscular junction disorders, as mentioned above. In CNS syndromes, voltage gated potassium channel (VGKC)-Abs were first identified by immunoprecipitation in Morvan's syndromes and then in non-paraneoplastic LE. ${ }^{15}{ }^{16}$ Voltage gated calcium channels (VGCC) and metabotropic glutamate receptor 1 (mGluR1) antibodies were found in some patients with cerebellar degeneration (see below). ${ }^{17} 18$ In LE, serum VGKC-Abs were also shown to label rodent hippocampus by indirect immunohistochemistry, ${ }^{16}$ and these and other serum or CSF antibodies that bind to the hippocampal molecular layer region rich in synaptic connections were subsequently designated 'neuropil' antibodies. ${ }^{19}$ A novel and frequent target is the NMDA sensitive glutamate receptor, ${ }^{20}$ while other less frequent neuropil antibodies are against $\boldsymbol{\alpha}$-amino-3-hydroxy-5-methyl-4-isoxazolepropionic acid (AMPA), ${ }^{21}$ gamma-aminobutyric acid $B$ $\left(\mathrm{GABA}_{\mathrm{B}}\right)^{22}$ and type 5 metabotropic glutamate (mGluR5) receptors. $^{23}$ Subsequently, it became clear that antibodies immunoprecipitating VGKC extracted from mammalian brain do not target the VGKC, as originally thought, ${ }^{16} 2425$ but proteins that are tightly complexed with VGKC in situ, mainly leucine rich glioma inactivated 1 protein (LGI1) or contactin associated protein 2 (CASPR2). ${ }^{26-28}$ Both of these proteins are expressed in the hippocampus although the localisation is subtly different. ${ }^{26}$ We now call these antibodies VGKC complex antibodies generically, or LGI1 and CASPR2 specifically. Contactin 2 is another component of the complex but antibodies to this protein are not very common. ${ }^{26}$

\section{Limbic encephalitis}

LE is a well recognised condition characterised by subacute development of short term memory loss, behavioural change and seizures involving the temporomedial lobes and the 
Table 2 Neuronal surface antibody associated syndromes

\begin{tabular}{|c|c|c|c|c|c|c|}
\hline Syndrome & Antibodies & Particular clinical features & Possible tumours & $\begin{array}{l}\text { Immunotherapy } \\
\text { response }\end{array}$ & $\begin{array}{l}\text { In vitro evidence of } \mathbf{A b} \\
\text { pathogenicity }\end{array}$ & $\begin{array}{l}\text { Frequency or No of } \\
\text { cases reported }\end{array}$ \\
\hline $\begin{array}{l}\text { NMDAR-Ab } \\
\text { encephalitis }\end{array}$ & NMDAR & $\begin{array}{l}\text { Dyskinetic movements, } \\
\text { decreased consciousness, } \\
\text { psychiatric presentation in } \\
\text { young women. Epilepsy and } \\
\text { abnormal movements more } \\
\text { frequent at onset in children }\end{array}$ & $\begin{array}{l}\text { Ovarian teratoma. Rare } \\
\text { in children. Up to } 50 \% \\
\text { after age } 18 \text { years }\end{array}$ & Yes & $\begin{array}{l}\text { In vitro and in vivo reduction } \\
\text { of NMDA receptors }\end{array}$ & $\begin{array}{l}\text { Common syndrome. } \\
\text { More than } 500 \text { cases } \\
\text { reported, mainly in USA }\end{array}$ \\
\hline \multirow[t]{4}{*}{ LE } & $\begin{array}{l}\text { LGI1 } \\
\text { CASPR2 } \\
(<10 \%)\end{array}$ & $\begin{array}{l}\text { Male predominance, hyponatraemia, } \\
\text { faciobrachial dystonic seizures, } \\
\text { myoclonus }\end{array}$ & $\begin{array}{l}\text { Rare with LGI1-Ab. } \\
\text { Thymoma in some } \\
\text { with CASPR2-Ab }\end{array}$ & Yes & $\begin{array}{l}\text { In vitro production of } \\
\text { epileptogenic activity in } \\
\text { brain slices }\end{array}$ & $\begin{array}{l}\text { Common syndrome } \\
\text { More than } 600 \text { cases } \\
\text { reported, mainly in UK }\end{array}$ \\
\hline & AMPAR & $\begin{array}{l}\text { Possible isolated psychiatric } \\
\text { symptoms }\end{array}$ & $\begin{array}{l}70 \% \text { (lung, breast, } \\
\text { thymus) }\end{array}$ & $\begin{array}{l}\text { Yes, frequent } \\
\text { relapses }\end{array}$ & $\begin{array}{l}\text { Downregulation of AMPA } \\
\text { receptors }\end{array}$ & 14 \\
\hline & $\mathrm{GABA}_{\mathrm{B}} \mathrm{R}$ & Prominent seizures & $60 \%$ (SCLC) & Yes & None & 25 \\
\hline & mGluR5 & Ophelia syndrome & Hodgkin lymphoma & Unknown & None & 2 \\
\hline $\begin{array}{l}\text { Morvan's } \\
\text { syndrome }\end{array}$ & CASPR2 & $\begin{array}{l}\text { Encephalopathy, peripheral } \\
\text { nerve hyperexcitability, } \\
\text { dysautonomia }\end{array}$ & Thymoma & Yes & Not tested & 9 \\
\hline PERM & GlyR & $\begin{array}{l}\text { Encephalomyelitis with } \\
\text { myoclonus, rigidity and } \\
\text { brainstem signs }\end{array}$ & Thymoma & Yes & Not tested & 6 \\
\hline \multirow[t]{2}{*}{$\begin{array}{l}\text { Cerebellar } \\
\text { ataxia }\end{array}$} & VGCC & $\begin{array}{l}\text { Possible coexistence } \\
\text { of LEMS }\end{array}$ & SCLC & Poor & Not tested & 16 \\
\hline & mGluR1 & $\begin{array}{l}\text { Remote history of Hodgkin } \\
\text { lymphoma }\end{array}$ & Hodgkin lymphoma & Yes & In vivo & 3 \\
\hline
\end{tabular}

The frequencies given depend on reported cases. Many cases are being diagnosed but are not reported.

$\mathrm{Ab}$, antibody; AMPA, $\alpha$-amino-3-hydroxy-5-methyl-4-isoxazolepropionic acid; AMPAR, $\alpha$-amino-3-hydroxy-5-methyl-4-isoxazolepropionic acid receptor; CASPR2, contactin associated protein 2; $\mathrm{GABA}_{\mathrm{B}} \mathrm{R}$, gamma-aminobutyric acid B receptor; GlyR, glycine receptor; LE, limbic encephalitis; LEMS, Lambert-Eaton myasthenic syndrome; LGI1-Ab, leucine rich glioma inactivated 1 protein antibody; mGluR, metabotropic glutamate receptor; NMDA, N-methyl-D-aspartate; NMDAR, N-methyl-D-aspartate receptor; PERM, progressive encephalomyelitis with rigidity and myoclonus; SCLC, small cell lung cancer; VGCC, voltage gated calcium channel.

amygdalae, with variable evidence of CSF inflammation and neuronal antibodies. ${ }^{2} 29$ For years it was considered a rare paraneoplastic disorder with a poor prognosis but it is now recognised that LE is frequently non-paraneoplastic. ${ }^{9}{ }^{30}$ In a few cases reported, a single clinical feature (eg, seizures, amnesia, delirium, psychosis) can be prominent or isolated; therefore, the concepts of autoimmune forms of encephalopathy, psychiatric disorders, epilepsy or dementia are beginning to be explored (for example, see Vincent et al, ${ }^{31}$ Flanagan et al, ${ }^{32}$ Vernino et al, ${ }^{33}$ Zandi et $a l^{34}$ and Kayser et $a l^{35}$ ).

\section{LE associated with VGKC complex antibodies}

VGKC-Abs associated LE was the first immunotherapy responsive NSAb associated CNS syndrome to be well characterised ${ }^{30} 36$ and since then it has become widely recognised. A high proportion of patients with LE have LGI1-Abs, and a few have CASPR2-Abs, but there are other VGKC complex proteins yet to be defined and the antibodies are best identified by the established radioimmunoprecipitation assay. ${ }^{24} 26$ Approximately $60 \%$ of patients have MRI evidence of medial temporal lobe inflammation but pleocytosis or other CSF changes are uncommon, and oligoclonal bands are rare. ${ }^{2630}$ Patients respond within a few weeks to intense immunotherapies with good or very good outcomes, but even without treatment a few patients have shown spontaneous improvement. ${ }^{16} 26$ Interestingly, a distinctive seizure semiology, termed faciobrachial dystonic seizures, can be identified before manifestation of LE, and these seizures respond rapidly to immunotherapies, which might prevent the onset of cognitive dysfunction and more widespread seizures in future cases. ${ }^{12}$

A rarer condition associated with VGKC-complex-Abs is Morvan's syndrome, characterised by insomnia and psychosis, peripheral nerve hyperexcitability (including neuromyotonia and pain) and dysautonomic features. ${ }^{15} 3738$ CASPR2-Abs are more common than LGI1-Abs in Morvan's syndrome but some patients have both specificities or neither. Around $40 \%$ of patients with Morvan's syndrome have tumours, often recurrent or malignant thymomas, sometimes associated with previous $\mathrm{MG}$, and these patients have a poor prognosis. However, those patients without tumours do well with immunotherapies. ${ }^{26}$

Less frequent NSAbs associated with LE

LE can also associate with antibodies against AMPA and $G_{A B A}$ receptors. ${ }^{21} 22$ These often have a classical LE phenotype and many have tumours, including SCLC, thyroid and breast tumours. There may be prominent psychiatric features with AMPA receptor antibodies (AMPAR-Abs) and prominent seizures with $G_{A B A}$ receptor antibodies ( $\left.G A B A_{B} R-A b s\right)$ but only small cases series have been reported so far. ${ }^{21} 22 \quad 3940$ $\mathrm{GABA}_{\mathrm{B}} \mathrm{R}-\mathrm{Abs}$ are probably the most common antibodies found in LE in association with SCLC, previously thought to be 'seronegative' for onconeural antibodies. ${ }^{40}{ }^{41}$ Most of the patients with $\mathrm{GABA}_{B} \mathrm{R}-\mathrm{Abs}$ or AMPAR-Abs who receive immunotherapy and cancer treatment show neurological improvement although relapses have been observed with AMPAR-Abs. ${ }^{21} 22$

Another novel NSAb has been recently described against type 5 mGluR (mGluR5) in two patients with prominent limbic encephalopathy and Hodgkin lymphoma (namely Ophelia syndrome). ${ }^{23}$

Although not NSAbs, GAD-Abs have been identified in younger females with a form of LE, presenting mainly with temporal lobe epilepsy and MRI evidence of temporal lobe inflammation; these patients did not usually respond well to immunotherapies but were not treated aggressively at onset. ${ }^{42}$

\section{NMDAR-Ab encephalitis}

The encephalitis associated with NMDAR-Ab is a well characterised and recognisable condition, distinct from the forms of LE 
described above. ${ }^{10}$ However, in distinction to most patients with typical LE, a high proportion of patients are children or young women who may initially be seen or admitted to psychiatric wards for acute anxiety, behavioural change or psychosis. Within a few days the presence of seizures or neuropsychological deficits is recognised, defining an organic condition, and within days or weeks reduced consciousness, movement disorders, hypoventilation and autonomic imbalance often require admission to intensive care units. ${ }^{10}$ Up to $50 \%$ of young adult female patients have an ovarian teratoma, but these are much less common in children. ${ }^{10}{ }^{11}$ Importantly, MRI is frequently not informative but pleocytosis at onset is very common. ${ }^{10}{ }^{11}$ In children, the disease can present with behavioural disturbance and dyskinesias ${ }^{43}$ and in the past such patients have often been classified as encephalitis lethargica. ${ }^{44}$ Relapses can occur in $20-25 \%$ of non-paraneoplastic patients and they can be separated by months or years. ${ }^{10} 11$

\section{PERM and GlyR-Ab associated conditions}

A few patients with a well recognised but rare condition, progressive encephalomyelitis with rigidity and myoclonus (PERM), which is part of the spectrum of SPS, ${ }^{45}$ have GAD-Abs but some are now being identified with antibodies against glycine receptors (GlyR-Abs). ${ }^{46-48}$ PERM was initially described as a subacute disorder characterised by muscle rigidity, stimulus sensitive spasms, brainstem dysfunction with poor prognosis and pathological findings (often post mortem) of perivascular lymphocyte cuffing and neuronal loss in the brainstem and spinal cord. Generalised myoclonus, hyperekplexia, cerebellar ataxia and autonomic dysfunction were later described. ${ }^{45} \mathrm{~A}$ few reports of GlyR-Abs in single cases and a series of three patients show a wide spectrum of features on presentation with often prominent brainstem dysfunction and little MRI or CSF evidence of inflammation ${ }^{46}{ }^{47}$; one patient presented with an immunotherapy responsive isolated medial temporal lobe status epilepticus (Zuliani et al in preparation). ${ }^{49}$ One had a thymoma, with dramatic improvement after surgery and immunotherapy. ${ }^{48}$ Despite the apparent rarity of the condition, patients with GlyR-Abs, in distinction to most of those with GAD-Abs, seem to do well on immunotherapies; however, one patient who also had NMDAR-Abs died before testing for either antibody was available. ${ }^{50}$

\section{Cerebellar ataxia associated with NSAbs}

Antibodies (VGCC-Abs) against voltage gated calcium channels (VGCC-Abs) were demonstrated to be present in some cases of cerebellar degeneration in association with lung tumours. ${ }^{17}$ However, the lack of response to immunotherapies, despite improvement of coexistent LEMS, suggested that the antibodies are unlikely to be contributing to the cerebellar pathology (or alternatively that they cause permanent Purkinje cell damage before treatment can be initiated). ${ }^{17} 51$ Antibodies to mGluR1 were initially reported in two patients with subacute cerebellar degeneration and a past history of Hodgkin disease and were shown in passive transfer to lead to ataxia in experimental animals. ${ }^{18}$ One other patient with this antibody without a tumour and with a partial treatment response has been reported. ${ }^{52}$ A recent study using a proteomic approach to identify potential NSAbs in patients with non-paraneoplastic cerebellar ataxia identified CASPR2-Abs in a total of nine of $88(10 \%)$ idiopathic ataxia patients compared with $2 \%$ in neurological controls. ${ }^{53}$ Systematic studies are required to examine the full repertoire of antibodies in this heterogeneous condition early during the disease course, and to test treatment responses.

\section{Proof of the pathogenicity of NSAbs}

Despite the very good clinical evidence that many of the syndromes described above are antibody mediated, there is little direct experimental evidence to prove this concept. There are studies on the effects of the serum or CSF IgG antibodies on neuronal function in cultured cells ${ }^{21} 5455$ or on brain slices ${ }^{56}$ but the transfer of clinical or electrophysiological evidence of disease to experimental animals by either systemic or intrathecal injection has not yet been reported, with the exception of mGluR1-Ab in paraneoplastic cerebellar degeneration, ${ }^{18}$ and reports of GAD or amphiphysin antibodies that target intracellular antigens (see below). ${ }^{57} 58$

\section{WELL DEFINED CNS SYNDROMES WITHOUT IDENTIFIED NSABS}

There are several syndromes which are well recognised and generally thought to be immune mediated but in which a potentially pathogenic antibody has not been defined. Below we remind the reader of these syndromes and recent work that may lead to discovery of relevant NSAbs.

\section{Stiff person syndrome and related disorders}

The autoimmune basis of SPS (reviewed by Meinck and Thompson ${ }^{45}$ ) is supported by response to immunomodulation, ${ }^{45} 59$ association with organ specific autoimmune diseases, high titre GAD-Abs (often intrathecally synthesised) ${ }^{7}$ or amphiphysin-Abs in paraneoplastic cases. ${ }^{60} 61$ A direct pathogenic role for antibodies against GAD and amphiphysin, both intracellular antigens, is controversial but successful passive transfer to rodents from patients both with GAD-Abs ${ }^{58}$ and amphiphysin-Abs ${ }^{57}$ are encouraging, in the latter case with evidence of internalisation of antibodies into the neurons. These experiments suggest that there are pathogenic antibodies that can access the presynaptic nerve terminal but more work needs to be done to define more clearly how this occurs, and the possibility of NSAbs coexisting with GAD-Abs needs to be explored.

\section{Opsoclonus-myoclonus syndrome}

Opsoclonus-myoclonus syndrome (OMS) is a rare disorder characterised by chaotic saccadic eye movements, myoclonus, ataxia and encephalopathy. It is best characterised in infants who often have neuroblastomas, but in some the disease appears to be non-paraneoplastic; the acute disease remits but the children are often left with cognitive and other problems. Immunotherapies appear to be of benefit but no systematic studies have been reported. There is also an idiopathic adult onset OMS, frequently in women, who have a monophasic course with a good response to intravenous immunoglobulins or corticosteroids. ${ }^{6}$ By contrast, a paraneoplastic form of OMS is more common in older women and associated with breast cancer and SCLC. ${ }^{63}$ Some evidence of possible NSAbs that are able to induce apoptosis of neuroblastoma cell lines has been shown in children but not in adults. ${ }^{64-67}$

\section{Cerebellar ataxia without identified NSAbs}

Post-infectious cerebellitis

This condition is well known in children ${ }^{68}$ but adult cases have also been reported. ${ }^{69}$ Like OMS, it tends to improve spontaneously but often leaves long term deficits, especially in adults. ${ }^{69}$ Most cases are not associated with any identified antibody although autoantibodies cross reacting with Epstein-Barr virus have been reported, ${ }^{70}$ and autoimmune mechanisms are likely. 
Cerebellar ataxia associated with antibodies against non-onconeural intracellular antigens

In cases of cerebellar ataxia without evidence of a tumour or onconeural antibodies, there is some evidence for potential autoimmune mechanisms. Antibodies against intracellular antigens have been reported in patients with non-paraneoplastic cerebellar ataxia (eg, Homer3) ${ }^{71} 72$ and also with coexisting coeliac disease/gluten sensitivity (ie, antigliadin antibodies cross reacting with cerebellar antigens) although the latter hypothesis remains controversial. ${ }^{73}$ In addition, a more insidious course is described in non-paraneoplastic GAD-Ab associated cerebellar syndromes in which an autoimmune mechanism is further supported by CSF inflammation and polyendocrine autoimmunity. ${ }^{74}$ In each of these situations the possibility of NSAbs should be considered in the future.

\section{OTHER POSSIBLE NSAS}

There are many reports of patients in whom an NSAb mediated mechanism may be present even though they do not present as one of the conditions described above. For example, there are patients reported with epilepsy ${ }^{75-77}$ or psychosis ${ }^{34} 3578$ with GAD, VGKC complex or other NSAbs; others with GAD-Ab associated nystagmus ${ }^{79}$ or palatal tremor. ${ }^{80-82}$ Moreover, there are CNS disorders for which a role for autoantibodies has been hypothesised but is still controversial. These include poststreptococcal neurological and psychiatric syndromes, Sydenham's chorea with antibodies targeting 'basal ganglia antigens' and also encephalopathies associated with systemic autoimmunity (ie, antiphospholipid syndrome and neuropsychiatric lupus) or organ specific conditions for which a vasculitic or ischaemic mechanism can be excluded. ${ }^{83}$ Hashimoto's encephalopathy, also called steroid responsive encephalopathy associated with autoimmune thyroiditis, is an example of the latter group and is only defined by the presence of serum thyroperoxidase or thyroglobulin antibodies, often without evidence of thyroid dysfunction. ${ }^{84}$ Given the high frequency of thyroid antibodies in the normal population, it is likely that in some cases they are incidental and that NSAbs are the real pathogenic agent; indeed, thyroid antibodies were found coexisting with NMDAR or VGKC-complex-Abs in a recent study of LE. ${ }^{85}$ Finally, there are many forms of childhood encephalitis and epilepsy which are often treated with steroids but are not yet recognised as antibody mediated, although cases with VGKC complex, GAD or NMDAR-Abs are beginning to be reported. ${ }^{86} 87$ Below we consider how one might go about recognising these conditions and defining NSAS for future diagnosis and management.

\section{ANTIBODY SCREENING}

Indirect immunohistochemisty or immunofluorescence on fixed and/or frozen rat brain tissue is commonly used as a preliminary screen to identify recognisable staining patterns that represent intracellular or surface (eg, neuropil) antibodies, although sensitivity, particularly for the latter, depends on laboratory expertise. The target of the antibodies may be strongly suspected from these results, but should be confirmed by more specific techniques. Commercial assays for immunoblotting with recombinant proteins for the most common/well characterised onconeural antibodies (Hu, Ma2, CV2/CRMP5, Ri, amphiphysin) are widely available. GAD-Abs and VGKC complex antibodies are often detected by radioimmunoassay but a GAD$\mathrm{Ab}$ ELISA and a GAD-Ab immunoblot test are also available.

The gold standard for NSAb detection (and for other antibodies against cell surface antigens-eg, AOP4) is an assay based on mammalian cells (generally human embryonic kidney cells) transiently transfected with the antigen of interest and incubated with the patient's serum, diluted 1:10 or greater (or CSF, usually diluted from 1:1-1:10). Positive samples are visually identified at the (unpermeabilised) cell surface or throughout the (permeabilised) cell using an antihuman IgG tagged with a fluorescent dye. This technique, commonly named a cell based or cell binding assay, is sensitive and specific, as only one antigenic target is overexpressed in these cells.

Given the plethora of antibodies that have been reported so far, the clinician faced with the dilemma of which antibody to test first, especially if indirect immunohistochemisty or immunofluorescence gave inconsistent results, should bear in mind that most NSAb related CNS disorders are covered by NMDAR$\mathrm{Abs}$ and VGKC-complex Abs. If the sample proves negative for both, it may be worth referring to a laboratory with research experience in this area and requesting other antibodies. However, multiple antibody testing (for NMDAR, LGI1, CASPR2, AMPAR, GABA $A_{B}$ and GlyR) may be the way forward as there are now beginning to be commercial assays consisting of mosaics of cells displaying different NSAbs (similar to the single antibody test reported by Wandinger and colleagues ${ }^{88}$ ).

If no antibodies are positive with these specific tests, immunostaining of live hippocampal or other neurons may detect other NSAbs in patients. This approach, not yet available commercially, would allow detection of potentially pathogenic NSAbs, justify immunotherapies and could lead to identification of new antigens in the future.

\section{IMIMUNOTHERAPY}

There is no consensus or evidence base to indicate which type of immunotherapies should be tried in these patients but in well defined syndromes it is thought important to start early, without waiting for the results of the antibody determinations, and while screening of the tumour is conducted. First-line treatments are intravenous followed by oral high dose corticosteroids, intravenous immunoglobulins or plasma exchange, and frequently a combination of these (plasma exchange preceding intravenous immunoglobulins). Most patients with encephalitis associated with NSAbs respond within weeks of first-line treatments but responses can be slow in patients with NMDAR$\mathrm{Ab}$ encephalitis. For non-responders, if the tumour screen is negative, a second-line immunotherapy, with rituximab, cyclophosphamide, or both, has been suggested. ${ }^{10}$ There are no data on the value of chronic long term immunotherapy to prevent relapses in those syndromes that do so (mainly NMDAR-Ab encephalitis) although patients who are not treated with immunotherapy at the first event seem to have a higher risk for relapses. ${ }^{89}$ Based on the authors' experience, weaning should be very careful. Serial estimations of antibody levels, in serum and CSF if available, can be helpful.

\section{APPROACH TO THE RECOGNITION OF NSAS Well defined syndromes}

If the clinical features are typical of a well defined syndrome, such as LE or OMS, after exclusion of other potential causes (infective, trauma, toxic, metabolic, tumours or histories of previous CNS disease), the priority is to rule out a paraneoplastic syndrome, as previously established. ${ }^{2}$ A search for a tumour should be undertaken and testing of serum, and CSF if possible, performed for onconeural antibodies, for those NSAbs that are currently available (NMDAR, VGKC complex proteins) and also for GAD-Abs. If a tumour is found or if onconeural antibodies 
are positive, the syndrome will be a definite paraneoplastic neurological syndrome, ${ }^{2}$ and tumour therapy and immunotherapy can be performed. Irrespective of the presence of a tumour, a positive NSAb would justify the diagnosis of NSAS and more intensive immunotherapy; a screen for specific tumours should be intensified (eg, teratoma for NMDAR-Abs or thymoma for VGKC-Abs).

\section{Suspected NSAS}

In case of other neurological syndromes, the following three criteria can be used to suggest a possible immune mediated cause associated with an NSAb. Supportive features are not mandatory but their presence would strengthen the diagnostic suspicion and help the subsequent diagnostic classification.

Criteria

- Acute or subacute ( $<12$ weeks) onset of symptoms

- Evidence of CNS inflammation (at least one of):

- CSF (lymphocytic pleocytosis, CSF specific oligoclonal bands or elevated IgG index);

- MRI (eg, mediotemporal lobes FLAIR/T2 hyperintensities in case of a LE-like syndrome-otherwise unexplained (eg, post-seizure); or enhancement of cerebellar sulci) or functional imaging (hypermetabolism on fluorodeoxyglucose-positron emission tomography or hyperperfusion on single photon emission computed tomography in the acute-subacute phase);

- inflammatory neuropathology (lymphocytic infiltrates or other signs of immune activation) on biopsy.

- Exclusion of other causes (infective, trauma, toxic, metabolic, tumours, demyelinating or histories of previous CNS disease)

Supportive features

- History of other antibody mediated disorders (eg. MG) or organ specific autoimmunity.

- Preceding infectious, febrile illness or viral disease-like prodromes; this follows the recognition that (1) many cases of autoimmune encephalitis (eg, NMDAR) are preceded by prodromes and that (2) a CNS (as well as a peripheral nervous system) disorder with an acute or subacute onset following a viral disease can be generated by a parainfectious autoimmune mechanism.

As all of these conditions can associate with tumours, screening for onconeural antibodies should be performed. ${ }^{2}$ If a tumour is found or onconeural antibodies are positive, the syndrome will be a paraneoplastic neurological syndrome, definite or possible according to the Graus criteria. ${ }^{2}$ Meanwhile, a search for NSAbs and GAD-Abs should not be delayed, and while waiting for the results, a trial of immunotherapy can be started. Even in patients who are negative for the known NSAbs, a trial with steroids and

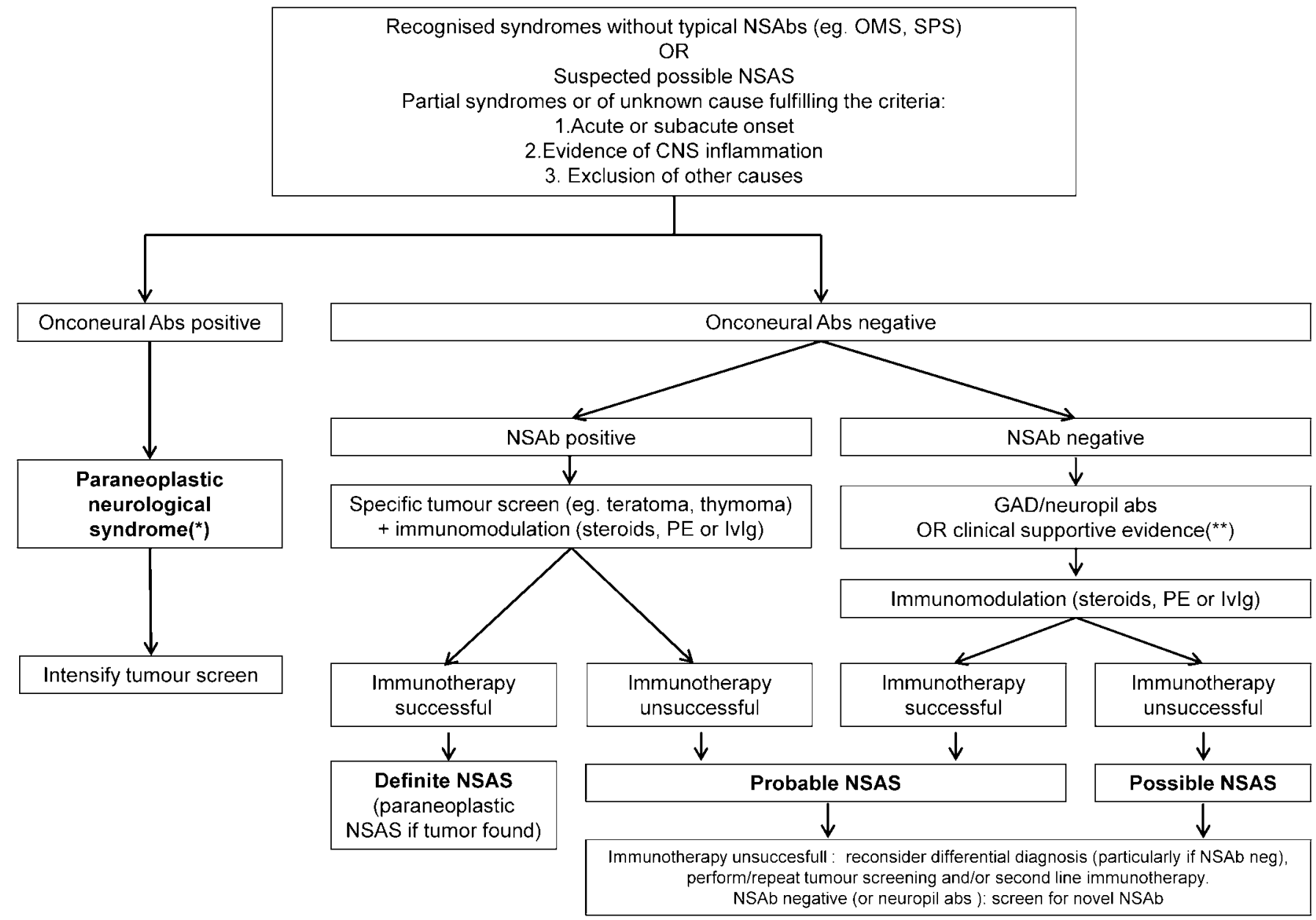

Figure 1 Flowchart indicating our suggestions for approaches to the recognition and diagnostic criteria for the neuronal surface antibody syndromes (NSAS). The field is developing and the scheme is intended to help identify further NSAS. *For details, see Graus et al. ${ }^{2}{ }^{* *}$ History of other antibody mediated disorders or organ specific autoimmunity, or previous infectious/febrile illness. GAD, glutamic acid decarboxylase; IVIG, intravenous immunoglobulins; NSAbs, neuronal surface antibodies; OMS, opsoclonus-myoclonus syndrome; PE, plasma exchange; SPS, stiff person syndrome. 
intravenous immunoglobulins or plasma exchange can be considered if there are no contraindications, particularly if infectious diseases have been ruled out.

Ultimately a diagnostic classification as definite, probable or possible NSAS will depend on the clinical presentation, antibody testing and response to immunotherapies (figure 1). Positive antibodies may sometimes be misleading, as very low titres (eg, $<1: 50$ ) can be found in patients with apparently unrelated conditions (unpublished results), but at present there are no standards for assessing the NSAbs and more data are needed to explore the relationships between titres and clinical features. To define a syndrome as immunotherapy responsive, a sustained improvement in the modified Rankin score of at least 1 point would be appropriate. ${ }^{5}$

The following diagnostic definitions are not only for 'classification' but are aimed at helping to justify systematic antibody testing, more intense immunotherapies and the search for novel NSABs.

\section{Classification}

- A diagnosis of definite NSAS can be made if known NSAbs are present in the serum or CSF AND there is a response to immunotherapies.

- A diagnosis of probable autoimmune NSAS can be made if: - known NSAbs are present

- OR there are other neuronal antibody markers of an immune process (GAD-Ab, unknown neuronal surface/ neuropil antibodies) or at least one of the above mentioned clinical supportive features AND there is a response to immunotherapies.

- If clinical and paraclinical criteria suggest a possible NSAS, but no known NSAbs are found, a diagnosis of possible autoimmune NSAS can still be made if:

- other neuronal antibody markers of an immune process (GAD-Ab, unknown neuronal surface/neuropil antibodies) or at least one of the above mentioned clinical supportive features are present

- OR there is a response to immunotherapies.

A diagnosis of probable or possible NSAS will prompt search for novel unknown antibodies or a second line immunotherapy (with or without tumour screening). An alternative diagnosis will be warranted in any other case (see figure 1).

\section{CONCLUSIONS}

This new field of immune mediated CNS diseases is exciting but also challenging. There is a need for more intense research into those conditions that are shown to be immunotherapy responsive and thereby can be defined as possible NSAS. The presence of these and other NSAbs in patients with more common conditions, such as epilepsy, psychosis and dementia, needs to be systematically examined. Ideally, antibody testing should be performed in local laboratories using internationally validated procedures so that the diagnosis can be made and treatments started as soon as possible in the hope of restoring health, limiting hospitalisation and optimising outcomes. Systematic studies of the treatments are needed in order to establish best practice.

Acknowledgements The authors are grateful to the Paraneoplastic Neurologic Syndrome Euronetwork for funding, and to all members of the PNS Euronetwork whose discussion and previous guidelines helped to shape this review (LZ, FG, BG, AV), the European Neurological Society (ENS) and the European Federation of Neurological Societies (EFNS) (LZ), the National Institutes of Health Research (NIHR) and Oxford Biomedical Research Centre (LZ, AV).
Contributors The review was invited by the editor and based on initial discussions between LZ, FG and AV. Additional comments and suggestions were received by BG and $\mathrm{CB}$, and all authors contributed to the final manuscript.

Funding This work was supported by personal fellowships to LZ from the European Neurological Society (ENS) and the European Federation of Neurological Societies (EFNS), and general support from the National Institutes of Health Research (NIHR) Oxford Biomedical Research Centre to AV

Competing interests AV and Oxford University hold patents for MuSK-Abs and for VGKC-complex Abs, and receive royalties and payments for antibody assays.

Provenance and peer review Commissioned; externally peer reviewed.

\section{REFERENCES}

1. Vincent A, Lang B, Kleopa KA. Autoimmune channelopathies and related neurological disorders. Neuron 2006;52:123-38.

2. Graus F, Delattre JY, Antoine JC, et al. Recommended diagnostic criteria for paraneoplastic neurological syndromes. J Neurol Neurosurg Psychiatry 2004; 75:1135-40.

3. Giometto B, Grisold W, Vitaliani R, et al. Paraneoplastic neurologic syndrome in the PNS Euronetwork database: a European study from 20 centers. Arch Neurol 2010;67:330-5.

4. Dalmau J, Rosenfeld MR. Paraneoplastic syndromes of the CNS. Lancet Neurol 2008; 7:327-40.

5. Graus F, Keime-Guibert F, Rene R, et al. Anti-Hu-associated paraneoplastic encephalomyelitis: analysis of 200 patients. Brain 2001;124:1138-48.

6. Graus F, Saiz A, Dalmau J. Antibodies and neuronal autoimmune disorders of the CNS. J Neurol 2009;257:509-17.

7. Saiz A, Blanco Y, Sabater L, et al. Spectrum of neurological syndromes associated with glutamic acid decarboxylase antibodies: diagnostic clues for this association. Brain 2008;131:2553-63.

8. Vincent A, Bien CG, Irani SR, et al. Autoantibodies associated with diseases of the CNS: new developments and future challenges. Lancet Neurol 2011;10:759-72.

9. Lancaster E, Martinez-Hernandez E, Dalmau J. Encephalitis and antibodies to synaptic and neuronal cell surface proteins. Neurology 2011;77:179-89.

9a. Bien CG, Vincent A, Barnet MH, et al. Immunopathology of autoantibody-associated encephalitides: clues for pathogenesis. Brain 2012 (In press)

10. Dalmau J, Lancaster E, Martinez-Hernandez E, et al. Clinical experience and laboratory investigations in patients with anti-NMDAR encephalitis. Lancet Neurol 2011;10:63-74.

11. Irani SR, Bera K, Waters $\mathrm{P}$, et al. N-methyl-D-aspartate antibody encephalitis: temporal progression of clinical and paraclinical observations in a predominantly nonparaneoplastic disorder of both sexes. Brain 2010;133:1655-67.

12. Irani SR, Michell AW, Lang B, et al. Faciobrachial dystonic seizures precede Lgi1 antibody limbic encephalitis. Ann Neurol 2011;69:892-900.

13. Lennon VA, Kryzer TJ, Pittock SJ, et al. IgG marker of optic-spinal multiple sclerosis binds to the aquaporin-4 water channel. J Exp Med 2005;202:473-7.

14. Brilot F, Dale RC, Selter RC, et al. Antibodies to native myelin oligodendrocyte glycoprotein in children with inflammatory demyelinating central nervous system disease. Ann Neurol 2009:66:833-42.

15. Liguori R, Vincent A, Clover L, et al. Morvan's syndrome: peripheral and central nervous system and cardiac involvement with antibodies to voltage-gated potassium channels. Brain 2001:124:2417-26.

16. Buckley C, Oger J, Clover L, et al. Potassium channel antibodies in two patients with reversible limbic encephalitis. Ann Neurol 2001:50:73-8.

17. Graus $\mathbf{F}$, Lang B, Pozo-Rosich $\mathrm{P}$, et al. $\mathrm{P} / \mathrm{Q}$ type calcium-channel antibodies in paraneoplastic cerebellar degeneration with lung cancer. Neurology 2002;59:764-6.

18. Sillevis Smitt $\mathbf{P}$, Kinoshita A, De Leeuw B, et al. Paraneoplastic cerebellar ataxia due to autoantibodies against a glutamate receptor. N Engl J Med 2000;342:21-7.

19. Ances BM, Vitaliani R, Taylor RA, et al. Treatment-responsive limbic encephalitis identified by neuropil antibodies: MRI and PET correlates. Brain 2005:128:1764-77.

20. Dalmau J, Tuzun E, Wu HY, et al. Paraneoplastic anti-N-methyl-D-aspartate recepto encephalitis associated with ovarian teratoma. Ann Neurol 2007;61:25-36.

21. Lai M, Hughes EG, Peng X, et al. AMPA receptor antibodies in limbic encephalitis alter synaptic receptor location. Ann Neurol 2009;65:424-34.

22. Lancaster $\mathbf{E}$, Lai $\mathrm{M}$, Peng $\mathrm{X}$, et al. Antibodies to the $\mathrm{GABA}(\mathrm{B})$ receptor in limbic encephalitis with seizures: case series and characterisation of the antigen. Lancet Neurol 2010;9:67-76

23. Lancaster E, Martinez-Hernandez E, Titulaer MJ, et al. Antibodies to metabotropic glutamate receptor 5 in the Ophelia syndrome. Neurology 2011;77:1698-701.

24. Hart IK, Waters C, Vincent A, et al. Autoantibodies detected to expressed $\mathrm{K}+$ channels are implicated in neuromyotonia. Ann Neurol 1997:41:238-46.

25. Kleopa KA, Elman LB, Lang B, et al. Neuromyotonia and limbic encephalitis sera target mature Shaker-type K+ channels: subunit specificity correlates with clinical manifestations. Brain 2006:129:1570-84.

26. Irani SR, Alexander S, Waters $\mathrm{P}$, et al. Antibodies to Kv1 potassium channelcomplex proteins leucine-rich, glioma inactivated 1 protein and contactin-associated protein-2 in limbic encephalitis, Morvan's syndrome and acquired neuromyotonia. Brain 2010;133:2734-48. 
27. Lai M, Huijbers MG, Lancaster $\mathrm{E}$, et al. Investigation of LGI1 as the antigen in limbic encephalitis previously attributed to potassium channels: a case series. Lancet Neurol 2010;9:776-85.

28. Lancaster $\mathbf{E}$, Huijbers MG, Bar V, et al. Investigations of caspr2, an autoantigen of encephalitis and neuromyotonia. Ann Neurol 2011;69:303-11.

29. Gultekin SH, Rosenfeld MR, Voltz R, et al. Paraneoplastic limbic encephalitis neurological symptoms, immunological findings and tumour association in 50 patients. Brain 2000;123:1481-94

30. Vincent A, Buckley C. Schott JM, et al. Potassium channel antibody-associated encephalopathy: a potentially immunotherapy-responsive form of limbic encephalitis. Brain 2004; 127:701-12.

31. Vincent $\mathbf{A}$, Irani SR, Lang B. The growing recognition of immunotherapy-responsive seizure disorders with autoantibodies to specific neuronal proteins. Curr Opin Neurol 2010;23:144-50.

32. Flanagan EP, McKeon A, Lennon VA, et al. Autoimmune dementia: clinical course and predictors of immunotherapy response. Mayo Clin Proc 2010;85:881-97.

33. Vernino S, Geschwind M, Boeve B. Autoimmune encephalopathies. Neurologist 2007:13:140-7.

34. Zandi MS, Irani SR, Lang B, et al. Disease-relevant autoantibodies in first episode schizophrenia. J Neurol 2010;258:686-8.

35. Kayser MS, Kohler CG, Dalmau J. Psychiatric manifestations of paraneoplastic disorders. Am J Psychiatry 2010:167:1039-50.

36. Thieben MJ, Lennon VA, Boeve BF, et al. Potentially reversible autoimmune limbic encephalitis with neuronal potassium channel antibody. Neurology 2004;62:1177-82

37. Josephs KA, Silber MH, Fealey RD, et al. Neurophysiologic studies in Morvan syndrome. J Clin Neurophysiol 2004;21:440-5.

38. Spinazzi M, Argentiero V, Zuliani L, et al. Immunotherapy-reversed compulsive, monoaminergic, circadian rhythm disorder in Morvan syndrome. Neurology 2008;71:2008-10.

39. Bataller L, Galiano R, Garcia-Escrig M, et al. Reversible paraneoplastic limbic encephalitis associated with antibodies to the AMPA receptor. Neurology 2010;74:265-7.

40. Boronat A, Sabater L, Saiz A, et al. GABA(B) receptor antibodies in limbic encephalitis and anti-GAD-associated neurologic disorders. Neurology 2011:76:795-800.

41. Alamowitch $\mathbf{S}$, Graus $F$, Uchuya $\mathbf{M}$, et al. Limbic encephalitis and small cell lung cancer. Clinical and immunological features. Brain 1997;120:923-8.

42. Malter MP, Helmstaedter $\mathrm{C}$, Urbach $\mathrm{H}$, et al. Antibodies to glutamic acid decarboxylase define a form of limbic encephalitis. Ann Neurol 2010;67:470-8.

43. Florance NR, Davis RL, Lam C, et al. Anti-N-methyl-D-aspartate receptor (NMDAR) encephalitis in children and adolescents. Ann Neurol 2009;66:11-18.

44. Dale RC, Irani SR, Brilot F, et al. N-methyl-D-aspartate receptor antibodies in pediatric dyskinetic encephalitis lethargica. Ann Neurol 2009;66:704-9.

45. Meinck HM, Thompson PD. Stiff man syndrome and related conditions. Mov Disord 2002;17:853-66

46. Hutchinson M, Waters P, McHugh J, et al. Progressive encephalomyelitis, rigidity, and myoclonus: a novel glycine receptor antibody. Neurology 2008;71:1291-2

47. Mas N, Saiz A, Leite Ml, et al. Antiglycine-receptor encephalomyelitis with rigidity. J Neurol Neurosurg Psychiatry 2010;82:1399-401.

48. Clerinx K, Breban T, Schrooten M, et al. Progressive encephalomyelitis with rigidity and myoclonus: resolution after thymectomy. Neurology 2011;76:303-4.

49. Zuliani L, Andrigo C, Leite Ml, et al. Immunotherapy-responsive status epilepticus with anti-glycine receptor antibody. 15th EFNS Congress; 2011. Budapest, Hungary, 2011.

50. Turner MR, Irani SR, Leite MI, et al. Progressive encephalomyelitis with rigidity and myoclonus: glycine and NMDA receptor antibodies. Neurology 2011;77:439-43.

51. Fukuda T, Motomura M, Nakao $\mathrm{Y}$, et al. Reduction of $\mathrm{P} / \mathrm{Q}$-type calcium channels in the postmortem cerebellum of paraneoplastic cerebellar degeneration with Lambert-Eaton myasthenic syndrome. Ann Neurol 2003:53:21-8.

52. Marignier R, Chenevier F, Rogemond V, et al. Metabotropic glutamate receptor type 1 autoantibody-associated cerebellitis: a primary autoimmune disease? Arch Neurol 2010;67:627-30.

53. Becker E, Zuliani L, Pettingill R, et al. Contactin-associated protein-2 antibodies in non-paraneoplastic cerebellar ataxia. J Neurol Neurosurg Psychiatry 2012:83:437-40.

54. Dalmau J, Gleichman AJ, Hughes EG, et al. Anti-NMDA-receptor encephalitis: case series and analysis of the effects of antibodies. Lancet Neurol 2008;7:1091-8.

55. Hughes EG, Peng X, Gleichman AJ, et al. Cellular and synaptic mechanisms of anti-NMDA receptor encephalitis. J Neurosci 2010;30:5866-75.

56. Lalic $T$, Pettingill $P$, Vincent $A$, et al. Human limbic encephalitis serum enhances hippocampal mossy fiber-CA3 pyramidal cell synaptic transmission. Epilepsia 2011;52:121-31.
57. Geis C, Weishaupt A, Hallermann S, et al. Stiff person syndrome-associated autoantibodies to amphiphysin mediate reduced GABAergic inhibition. Brain 2010;133:3166-80.

58. Manto MU, Laute MA, Aguera M, et al. Effects of anti-glutamic acid decarboxylase antibodies associated with neurological diseases. Ann Neurol 2007;61:544-51.

59. Dalakas MC, Fujii M, Li M, et al. High-dose intravenous immune globulin for stiff-person syndrome. N Engl J Med 2001;345:1870-6.

60. Folli F, Solimena M, Cofiell R, et al. Autoantibodies to a 128-kd synaptic protein in three women with the stiff-man syndrome and breast cancer. N Engl J Med 1993; 328:546-51.

61. Murinson BB, Guarnaccia JB. Stiff-person syndrome with amphiphysin antibodies: distinctive features of a rare disease. Neurology 2008;11:1955-8.

62. Bataller L, Graus F, Saiz A, et al. Clinical outcome in adult onset idiopathic or paraneoplastic opsoclonus-myoclonus. Brain 2001;124:437-43.

63. Bataller L, Rosenfeld MR, Graus F, et al. Autoantigen diversity in the opsoclonus-myoclonus syndrome. Ann Neurol 2003;53:347-53.

64. Blaes F, Fuhlhuber V, Korfei M, et al. Surface-binding autoantibodies to cerebellar neurons in opsoclonus syndrome. Ann Neurol 2005:58:313-17.

65. Korfei M, Fuhlhuber V, Schmidt-Woll T, et al. Functional characterisation of autoantibodies from patients with pediatric opsoclonus-myoclonus-syndrome. J Neuroimmunol 2005;170:150-7.

66. Sabater L, Xifro X, Saiz A, et al. Analysis of antibodies to neuronal surface antigens in adult opsoclonus-myoclonus. J Neuroimmunol 2008:196:188-91.

67. Blaes F, Pike MG, Lang B. Autoantibodies in childhood opsoclonus-myoclonus syndrome. J Neuroimmunol 2008;201-202:221-6.

68. Connolly AM, Dodson WE, Prensky AL, et al. Course and outcome of acute cerebellar ataxia. Ann Neurol 1994;35:673-9.

69. Klockgether T, Doller G, Wullner U, et al. Cerebellar encephalitis in adults. J Neurol 1993;240:17-20.

70. Uchibori A, Sakuta M, Kusunoki S, et al. Autoantibodies in postinfectious acute cerebellar ataxia. Neurology 2005;65:1114-16.

71. Zuliani L, Sabater L, Saiz A, et al. Homer 3 autoimmunity in subacute idiopathic cerebellar ataxia. Neurology 2007:68:239-40.

72. Hadjivassiliou M, Boscolo S, Tongiorgi $\mathrm{E}$, et al. Cerebellar ataxia as a possible organ-specific autoimmune disease. Mov Disord 2008;23:1370-7.

73. Hadjivassiliou M, Grunewald R, Sharrack B, et al. Gluten ataxia in perspective: epidemiology, genetic susceptibility and clinical characteristics. Brain 2003; 126:685-91.

74. Honnorat J, Saiz A, Giometto B et al. Cerebellar ataxia with anti-glutamic acid decarboxylase antibodies: study of 14 patients. Arch Neurol 2001;58:225-30.

75. Giometto B, Nicolao P, Macucci M, et al. Temporal-lobe epilepsy associated with glutamic-acid-decarboxylase autoantibodies. Lancet 1998-352:457.

76. Irani SR, Buckley C, Vincent A, et al. Immunotherapy-responsive seizure-like episodes with potassium channel antibodies. Neurology 2008;71:1647-8.

77. McKnight $\mathbf{K}$, Jiang $Y$, Hart $Y$, et al. Serum antibodies in epilepsy and seizure-associated disorders. Neurology 2005;65:1730-6.

78. Graus F, Boronat A, Xifro X, et al. The expanding clinical profile of anti-AMPA receptor encephalitis. Neurology 2010;74:857-9.

79. Antonini G, Nemni R, Giubilei F, et al. Autoantibodies to glutamic acid decarboxylase in downbeat nystagmus. J Neurol Neurosurg Psychiatry 2003;74:998-9.

80. Nemni R, Braghi S, Natali-Sora MG, et al. Autoantibodies to glutamic acid decarboxylase in palatal myoclonus and epilepsy. Ann Neurol 1994;36:665-7.

81. Vianello M, Morello F, Scaravilli T, et al. Tremor of the mouth floor and anti-glutamic acid decarboxylase autoantibodies. Eur J Neurol 2003;10:513-14.

82. Marnane M, Vincent A, Hutchinson M. New-onset focal epilepsy with palatal tremor and glutamic acid decarboxylase antibodies responding to intravenous immunoglobulin. J Neurol 2008;255:1603-4

83. Lang B, Dale RC, Vincent A. New autoantibody mediated disorders of the central nervous system. Curr Opin Neurol 2003;16:351-7.

84. Chong JY, Rowland LP, Utiger RD. Hashimoto encephalopathy: syndrome or myth? Arch Neurol 2003:60:164-71.

85. Tuzun E, Erdag E, Durmus $\mathrm{H}$, et al. Autoantibodies to neuronal surface antigens in thyroid antibody-positive and -negative limbic encephalitis. Neurol India 2011:59:47-50.

86. Suleiman J, Brenner T, Gill D, et al. VGKC antibodies in pediatric encephalitis presenting with status epilepticus. Neurology 2011;76:1252-5.

87. Haberlandt $\mathbf{E}$, Bast T, Ebner A, et al. Limbic encephalitis in children and adolescents. Arch Dis Child 2011;96:186-91.

88. Wandinger KP, Saschenbrecker S, Stoecker W, et al. Anti-NMDA-receptor encephalitis: a severe, multistage, treatable disorder presenting with psychosis. J Neuroimmunol 2011;231:86-91.

89. Gabilondo I, Saiz A, Galan L et al. Analysis of relapses in anti-NMDAR encephalitis. Neurology 2011;77:996-9. 